This item was submitted to Loughborough's Research Repository by the author.

Items in Figshare are protected by copyright, with all rights reserved, unless otherwise indicated.

\title{
Graphic design research: a cause for the concerned
}

PLEASE CITE THE PUBLISHED VERSION

PUBLISHER

Design Research Society

VERSION

VoR (Version of Record)

PUBLISHER STATEMENT

This work is made available according to the conditions of the Creative Commons Attribution-NonCommercialShareAlike 4.0 International (CC BY-NC-SA 4.0) licence. Full details of this licence are available at: http://creativecommons.org/licenses/by-nc-sa/4.0/

\section{LICENCE}

CC BY-NC-SA 4.0

\section{REPOSITORY RECORD}

Harland, Robert G., James Corazzo, lan Gwilt, Alison Honnor, and Steve Rigley. 2019. "Graphic Design Research: A Cause for the Concerned". figshare. https://hdl.handle.net/2134/34105. 


\title{
Graphic design research: a cause for the concerned
}

\author{
HARLAND Robert George ${ }^{\mathrm{a}^{*}}$; CORAZZO James $^{\mathrm{b}}$; GWILT Ian ${ }^{\mathrm{c}}$; HONNOR Alison ${ }^{\mathrm{d}}$; RIGLEY Steve ${ }^{\mathrm{e}}$ \\ ${ }^{a}$ Loughborough University \\ ${ }^{\text {bd }}$ Sheffield Hallam University \\ ${ }^{c}$ University of South Australia \\ ${ }^{\mathrm{e}}$ Glasgow School of Art \\ *r.g.harland@lboro.ac.uk \\ doi: 10.21606/dma.2017.389
}

\begin{abstract}
There is an immediate need to clarify and develop the role of graphic design research for the theoretical underpinning of graphic design education. A report that accompanied the 2014 UK Research Excellence Framework (REF2014) described 'the intellectual and theoretical underpinning of graphic and communication design' as 'generically weak'. We report on progress about a project designed to identify and map graphic design outputs from REF2014, involving both a data analysis of the 'Art and Design: History, Practice and Theory' submissions, and focus group research with graphic design academics designed to elicit feedback on the emergent themes being addressed by the data analysis exercise as well as broader concerns. The aim has been to identify the nature of graphic design outputs submitted to the REF audit. In this paper, we provide a response to this state of affairs from a community of graphic design educators concerned about the perception of research in the discipline.
\end{abstract}

Keywords: Graphic design research, Graphic design education, Research Excellence Framework, Graphic Design Educators' Network

\section{Introduction}

In the most recent national review of research in the United Kingdom (UK) the discipline of graphic design, framed within the wider setting of 'graphic and communication design', was reported to show little, if any, signs of improvement since the 2008 Research Assessment Exercise. Despite an improved showing for Art and Design in the 2014 Research Excellence Framework (REF), the Panel Overview Report for Unit of Assessment (UoA) 34 (Art and Design: History, Practice and Theory) noted 'while there were high quality exceptions, the intellectual and theoretical underpinning of graphic and communication design was thought to be generically weak' (HEFCE 2014: 85). During the same period, graphic design continued to be the most popular discipline in the Art \& Design higher education sector in the UK. A course search of the university admissions service, UCAS, returned 151 graphic design undergraduate programmes for the academic year 2016/17.

1. This work is licensed under a Creative Commons Attribution-NonCommercial-Share Alike 4.0 International License.

2. https://creativecommons.org/licenses/by-nc-sa/4.0/ 
These opposing positions provide the impetus for this paper as we attempt to understand some of the reasons why this discipline has not been able to respond to the challenge of recent national research excellence reviews.

We report on progress about a project designed to identify and map graphic design outputs from REF2014 main panel D sub panel UoA 34. This initially involved qualitative data analysis of the 2014 UoA 34 submission narratives, but also extends to focus group discussion with graphic design academics to explore their perceptions, feelings and ideas about the REF2014 findings related to the discipline.

The aim of the data analysis has been to assess to what extent remarks in the REF2014 overview report that graphic and communication design outputs were 'generically weak' were justified. Preliminary findings from the data analysis process are shared here, and also formed the starting points for a wider discussion about a community response to an unsatisfactory research performance. By sharing early findings from this project, we hope to raise the profile of these concerns for the benefit of educators in graphic design, communication design, art and design, and those in higher education management positions who are also interested in why this is a recurring issue.

The paper is structured in two parts. First, we present early findings from the REF2014 data analysis exercise, explaining the origin of the project, aims, methods and initial findings. Second, we report on a focus group discussion with graphic design educators who were introduced to preliminary findings from the data analysis. In this second part, we outline issues, some familiar but some less so, that arose in response to questions about why REF performance is considered 'weak'. We extend the discussion by responding to a range of familiar concerns arising from the focus group, such as problems with nomenclature, the need for research in a practice-based subject, and concomitant issues such as workload priorities.

\section{Analysis of graphic design research as submitted to REF2014: initial findings}

REF2014 assessed the quality of research in all disciplines across all Higher Education Institutions (HEIs) in the UK. Research was assessed under three headings:

Outputs (up to 4 research outputs per researcher, $65 \%$ of overall score),

Impact (research leading to change or benefit outside academia, at least 2 per HEI linked to headcount, $20 \%$ of overall score)

Environment (a statement on staffing, strategy, infrastructure and other measures, contributing $15 \%$ to overall score)

The census period for REF2014 ran from 1 January 2008 to 31 December 2013 with a submission date of 29 November 2013. Submission data, therefore, provides a snapshot of HE research activity in the UK for the census period at the end of 2013. Results were published in December 2014 along with overview reports at Main Panel and Unit of Assessment level. These are available to view by UoA or by HEI on the REF2014 website (see http://www.ref.ac.uk/2014/), however, individual scores for outputs are not available. Research outputs were assessed using a star rating system reflecting quality as follows: $4 *$ world-leading, $3 *$ internationally excellent, $2^{*}$ recognised internationally, $1^{*}$ recognised nationally, and unclassified falling below the standard of nationally recognised work or did not meet the definition of research as defined by the REF assessment criteria. Submissions were made by $154 \mathrm{HEls}$ to 36 Units of Assessment (UoAs) clustered under 4 Main Panels (A-D). There were 84 institutional submissions to UoA34 Art \& Design: History, Practice and Theory, which formed part of Main Panel D: Arts \& Humanities. Sub-panel 34 assessed 6,356 outputs across 21 output types (listed further on in this article). Table 1 provides a breakdown of the UoA34 average quality profiles (see Main Panel D report at 
http://www.ref.ac.uk/2014/media/ref/content/expanel/member/Main\%20Panel\%20D\%20overview \%20report.pdf).

Table 1 Quality profiles for UoA 34.

\begin{tabular}{|l|l|l|l|l|l|}
\hline & $4^{*}$ & $3^{*}$ & $2^{*}$ & $1^{*}$ & Unclassified \\
\hline Overall quality & $\mathbf{2 6 . 0}$ & $\mathbf{4 2 . 0}$ & $\mathbf{2 5}$ & $\mathbf{6 . 0}$ & $\mathbf{1}$ \\
\hline Outputs & 18.5 & 42.6 & 30 & 7.7 & 1.2 \\
\hline Impact & 36.6 & 44.7 & 13.6 & 3.9 & 1.2 \\
\hline Environment & 40.5 & 40.8 & 15.5 & 3.0 & 0.2 \\
\hline
\end{tabular}

All REF2014 submission data, with the exception of staff contractual details, was made publically available in January 2015. Output data and staff data were published separately and so it is not possible to link outputs to individual staff names.

As noted above, in their overview report of the assessment of UoA34, the sub-panel noted weakness in 'the intellectual and theoretical underpinning of graphic and communication design' (REF2014). In the light of this, the authors of this paper approached the Council for Higher Education in Art \& Design (CHEAD) about this concern. CHEAD commissioned researchers from [Institution A], [Institution $B$ ] and [Institution $C$ ] to undertake a retrospective analysis of outputs submitted to UoA34 in REF2014 to assess the contribution of research from the Graphic Design sector. The project was formally announced at the CHEAD Research Alliance Symposium 2: Approaches to Design Research at Sheffield Hallam University, in February 2017, and work began on data analysis soon after. Subsequent research team meetings happened throughout the summer both face-to-face and virtually, culminating in the focus group session at the Graphic Design Educators' Network annual conference in 2017, 7-8th September, also at Sheffield Hallam University.

\subsection{Methods}

Analysis focused on the outputs data for submissions to UoA34 issued from the REF2014 website on an MS Excel spreadsheet. Of the 6,356 outputs assessed by the sub-panel, 6,321 are publically available after the removal of outputs flagged as confidential (for commercial or other reasons). It is important to note that HEls were free to select which staff and outputs to include in each UoA, so REF2014 outputs do not provide the full picture of all research activity within any given discipline.

To categorise relevant outputs as originating in graphic design research, keyword searches were conducted both on all output titles and 'additional information' fields where used (see Table 2). The 'additional information' field provided the space (max. 300 words) to clarify the research element of outputs, particularly where the nature and extent of the research were not immediately evident. However, in the case of text-based output types (authored books, book chapters, journal articles etc.) this field was rarely used since the research element would be considered self-evident. Attention was paid to text-based outputs where no additional information was supplied to ensure significant numbers of outputs were not missed or incorrectly categorised. In fact, only 30 outputs were identified using the keyword search based on the title where 'Additional Information' was added (all text based). In these cases, library searches were used to assess whether the output stemmed from graphic design research.

A mix of approaches was used to extract the relevant outputs from the spreadsheet of submissions to UoA34. Following initial keyword searches, the project team reviewed the results to assess relevance and suitability. This made the way for a reflexive, iterative process of keyword searches with results refined in line with requirements of the analysis and patterns and categories emerging from the data (it should be noted this work is on-going and, at the time of writing, patterns and themes still emerging and being reviewed and the dataset is yet to be finalised). 


\subsubsection{Keywords}

A shortlist of terms relating to graphic design research was drawn up by the project team (see Table 2) and keyword searches of the UoA34 submissions spreadsheet were carried out. A sample of outputs containing these key search terms was reviewed by the project group to assess their relevance and suitability. In addition to keywords suggested by the project team, other methods of identifying relevant outputs were used. For example, attention was given to outputs from prominent departments in the field (specifically the Department of Typography and Graphic Communication at the University of Reading).

Table 2 List of keywords

\begin{tabular}{|l|l|l|l|}
\hline Advertising & History of graphic design & Letterpress & Typeface \\
\hline Branding & Illustration & Lithographic & Type design \\
\hline Calligraphy & Imaging & Manuscript & Typography \\
\hline Cartography & Information design & Print history & Visual communication \\
\hline Communication design & Inscription & Print process / printing process & Visual design \\
\hline Graphic design & Interaction design & Page design & Visual media \\
\hline Graphics & Interaction + design & Printmaking & Visualisation \\
\hline Graphic & Legibility & Signage & Wayfinding \\
\hline
\end{tabular}

Some keyword terms - initially envisioned as critical elements of graphic design research - emerged on review as falling almost entirely beyond the boundaries of the discipline. For example, one of the earliest findings was that the categories of 'co-design', 'design thinking' and 'service design' were unlikely to have been used to describe outputs from graphic design research. Thus, precise categorisation of outputs was problematic: many outputs with a graphic design element emerge from interdisciplinary work and may borrow terminology from beyond the discipline, however in many cases 'graphic design' terminology might be used to describe research from other disciplines. In cases where research crossed-boundaries it was necessary to review the additional details to ensure there was a graphic or communication design basis for the research. In cases of 'borrowed terminology' further keyword searches were run to eliminate outputs from beyond the boundaries of graphic design. For instance, it emerged that the term 'visualisation' was frequently used in 'additional information' provided for outputs from fine art practice and dance performance.

Overlaps between research categories have been accounted for by admitting multiple categorisations so that an output might feature in both 'Advertising' and 'Visualisation' or 'Communication Design, 'Print History' and 'Typography'.

\subsubsection{Research Groups}

Submitting institutions were not required to provide information on the disciplinary origin of outputs, although there was an option to allocate a 'research group' to outputs. 19 of the 84 submitting institutions opted to use this category, and this was predominantly to reflect strategic research themes or internal organisation. None was dedicated solely to graphic design-based research, and so this was judged not to be a helpful category for this research.

\section{Initial findings}

While the current dataset is still a work in progress, over two-thirds of HEls submitting to REF2014 had a least one graphic design output (currently 57 out of 84 institutions [67.9\%] submitted at least one output featuring a graphic design related keyword). Table 3 confirms a total of 306 outputs out of 6,321 have been identified as featuring graphic design research. That is $4.84 \%$ of the total submission to UoA34: Art and Design (History, Practice \& Theory). There are strong parallels with the rest of the UoA34 Submission for output types, despite representing only $4.84 \%$ of submission. In addition it is clear that the distribution of graphics outputs closely maps onto the spread of output types submitted to the whole of UoA34. For example, the five most commonly used output types 
('Journal Article', 'Exhibition', 'Chapter in Book', 'Artefact' and 'Authored Book') were the same for both graphic design related outputs and for art and design outputs as a whole. At this stage, it would appear the graphic design discipline used the 'Exhibition' and 'Chapter in Book' categories slightly less than the sector as a whole, although submitted a significantly larger proportion to the 'Design' output type (3.39\% versus $1.12 \%$ for UoA34). See Figure 1 for a more visual display of the data.

Table 3 Provisional numbers for graphics

\begin{tabular}{|c|c|c|c|c|}
\hline Output type & Number in UoA34 & Percentage of UoA34 & $\begin{array}{l}\text { Number of Graphics } \\
\text { outputs }\end{array}$ & $\begin{array}{l}\text { Percentage of } \\
\text { Graphics outputs }\end{array}$ \\
\hline A - Authored book & 658 & $10.35 \%$ & 39 & $12.75 \%$ \\
\hline B - Edited book & 228 & $3.59 \%$ & 13 & $4.25 \%$ \\
\hline C - Chapter in book & 1,096 & $17.24 \%$ & 47 & $15.36 \%$ \\
\hline R - Scholarly edition & 7 & $0.11 \%$ & 0 & $0.00 \%$ \\
\hline D - Journal article & 1,633 & $25.69 \%$ & 98 & $32.03 \%$ \\
\hline E Conference contribution & 197 & $3.10 \%$ & 15 & $4.90 \%$ \\
\hline U Working paper & 4 & $0.06 \%$ & 0 & $0.00 \%$ \\
\hline L Artefact & 679 & $10.68 \%$ & 27 & $8.82 \%$ \\
\hline P Devices and products & 19 & $0.30 \%$ & 0 & $0.00 \%$ \\
\hline M Exhibition & 1,139 & $17.92 \%$ & 26 & $8.50 \%$ \\
\hline I Performance & 119 & $1.87 \%$ & 2 & $0.65 \%$ \\
\hline F Patent/ published patent application & 23 & $0.36 \%$ & 0 & $0.00 \%$ \\
\hline J Composition & 18 & $0.28 \%$ & 0 & $0.00 \%$ \\
\hline K Design & 71 & $1.12 \%$ & 15 & $4.90 \%$ \\
\hline N Research report for external body & 38 & $0.60 \%$ & 2 & $0.65 \%$ \\
\hline O Confidential report for external body & 15 & $0.24 \%$ & 0 & $0.00 \%$ \\
\hline G Software & 5 & $0.08 \%$ & 2 & $0.65 \%$ \\
\hline H Website content & 30 & $0.47 \%$ & 0 & $0.00 \%$ \\
\hline Q Digital or visual media & 205 & $3.23 \%$ & 7 & $2.29 \%$ \\
\hline S Research datasets and databases & 4 & $0.06 \%$ & 0 & $0.00 \%$ \\
\hline \multirow[t]{2}{*}{ T Other } & 168 & $2.64 \%$ & 13 & $4.25 \%$ \\
\hline & 6,356 & $100.00 \%$ & 306 & $100.00 \%$ \\
\hline
\end{tabular}

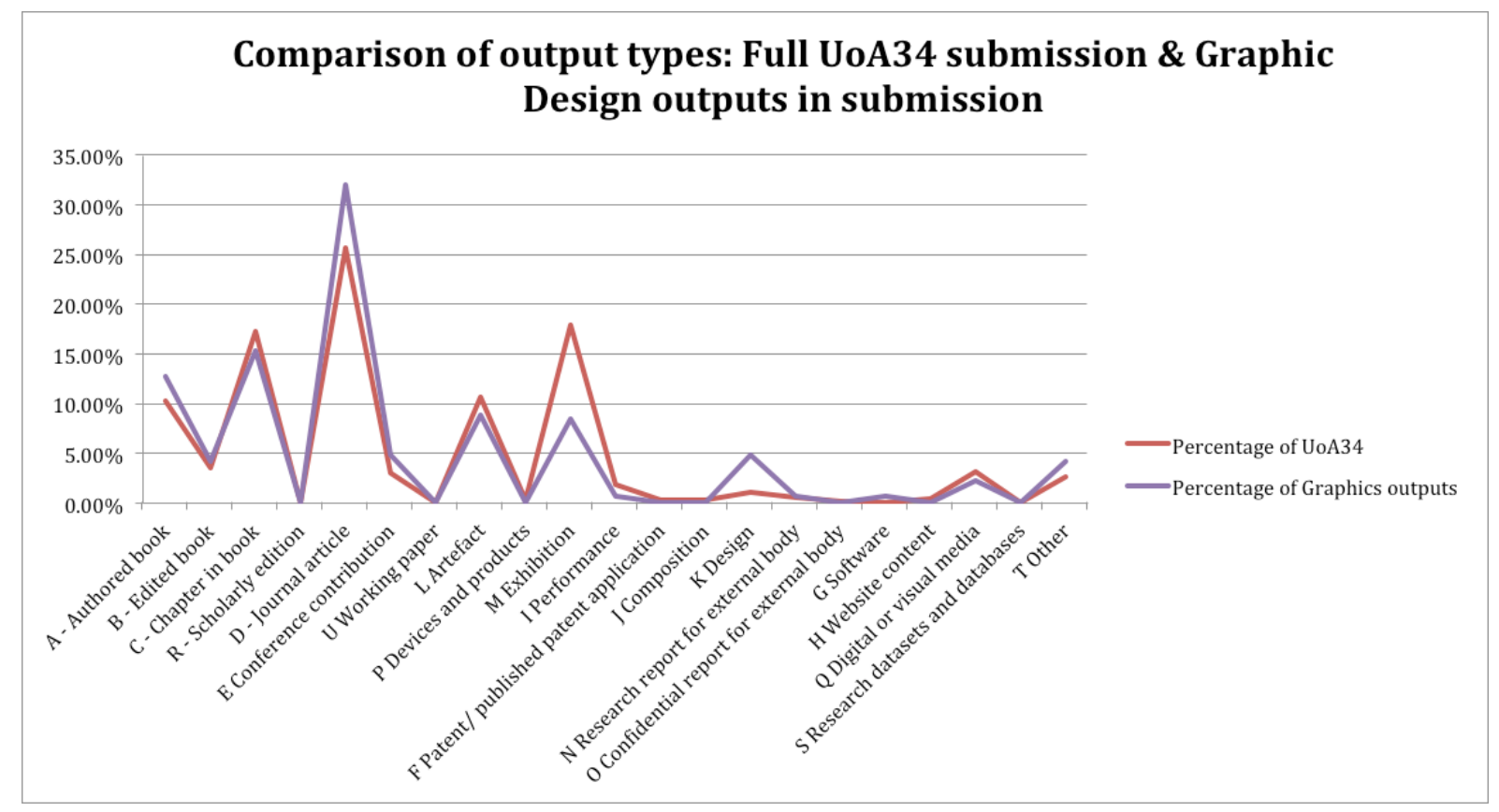

Figure 1 Comparison of output types 


\section{Focus group discussion}

At the early stage of data analysis the motives for the project were shared with twenty graphic design educators at the Graphic Design Educators' Network annual conference, noted earlier. Focus groups are useful for establishing whether there is a consensus about new areas of research and gaining quick responses and contrasting views to specific topics (Denscombe 2007: 180). In this section, we highlight responses to the claims of poor REF2014 performance from graphic design educators, and offer some further commentary in response to these issues.

The focus group session invited responses to the statement in the REF2014 Panel Overview report. Participants were invited to respond to the question 'What possible explanations might there be for this 'weakness'? Furthermore, set against the assertion that 'Graphic design research ... is thriving, if you know where to look' (Walker, 2017), participants were invited to comment on where, in their experience, could it be found? The session convenors began with an acknowledgement about whether there might be a link between the high volume of teaching undertaken by most graphic design academics and the small amount of research produced. This was agreed to be the case.

When pressed further about what possible explanations there might be for 'weakness' the following concerns were voiced:

- Graphic Design is a practice-based, pragmatic discipline and as such does not fit with traditional academic research.

- Graphic Design outputs may not be formally aligned to specific Graphic Design themes, but instead may be placed under more discipline specific practices such as photography or film.

- Being recognised for excellent research is not considered necessary / essential / relevant for a Graphic Design academic (unlike many other academic disciplines that attract much higher levels of grant capture).

- Graphic Design - no agreed use of name.

- Teaching workloads - when other disciplines are gearing down from teaching hours towards a semester of research and other activities, Graphic Design academics are gearing up for more teaching / graduate shows etc.

- Graphic Design is younger discipline and practice-based research degrees still relatively new.

- There are very few Graphic Design academics in university REF teams (more often architects, fine artists, or art historians).

- Does Graphic Design need more representation on REF panels?

A number of issues arise from these points that allude in part to explanations about why REF performance is less than satisfactory, some of which may apply to other applied fields of design. The following is offered as additional thoughts about why the situation is as it is.

During the focus group, it was recognised that graphic design is not alone in being a practice-based discipline, and one need only look towards programmes taught in the same environment that have more successfully embraced a research agenda, such as product design or fine art. Comparison, of course, is not necessarily like-for-like. For example, product design has responded to a decline in a UK manufacturing base over the past few decades by significantly expanding to include emergent areas such as user-experience design or service design.

With regard to the lack of a strong disciplinary focus for graphic design, this reveals not how easy graphic design is to do as a solo activity but how difficult it is to understand its integrative nature. 'Collaborative', 'integrative', and 'combining' are all terms that have been used to describe a practice that is not media specific (Harland 2016: 17-22) but is predominantly interdisciplinary by nature, alluding to the way 'different areas of knowledge within the same discipline' come together 
(Muratovski 2016: 19). Indeed, practitioners in graphic design claim to engage with a wide range of activities (van der Waarde 2009: 5) suggesting a basic training in the field provides many opportunities for practice compared to traditional academic subjects (see Table 4). Hence, if it has a lack of strong disciplinary focus, this is because the boundaries around the space it occupies overlap with more singular pursuits. Its emphasis on plurality, rather than singularity, provides the key to understanding its objects as a combination of different things that somehow work together. Some of these things are not exclusively graphic design practices, such as end user research, or house style management. It should not therefore be surprising if researchers are active in areas that are/are not labelled graphic design.

Table 4 The activity of graphic designers (adapted from van der Waarde 2009: 5)

\begin{tabular}{|l|l|l|}
\hline Illustration & Infographics & Marketing \\
\hline Photography & Font design & Usability \\
\hline Typography & Desktop publishing & End user research \\
\hline Copywriting & Film production & Visual research \\
\hline Image processing & Website design & Visual strategy \\
\hline Animation & Graphic Art & Concept development \\
\hline Audio-visual & Spatial design & House style management \\
\hline Programming & Advertising & Project organisation \\
\hline Author & House style design & Communication strategy \\
\hline
\end{tabular}

The issue of whether excellence in research is necessary/essential/relevant for the graphic design academic raises interesting issues. Like many professional knowledge curriculums, graphic design faces two ways (Bernstein 2000) - towards the vocational nature of graphic design and professional practice and alternatively as an academic subject that is understood as a 'visual form of knowledge production' (Drucker 2014). Comparisons can be made to the way dentists or doctors are trained, the way their programmes are characterised, and the way research contributes to the practice. For example, a doctor studies medicine and a dentist studies dental surgery, yet those subjects thrive on research contributing to the evolution of the practice. A simple response here is how can research be dismissed so readily when graphic design is now taught so often as a university subject? Is it that it is not worthy of research? Or, that we do not yet fully understand how research might influence and impact on graphic design practice?

On the matter of name, the issue of 'no agreement' is contentious not only for those involved with teaching across the variations in programme titles that have emerged since the early 1990s, but also for those external to the field who struggle to understand a subject in a seemingly constant state of flux. Positions around terminology and acceptance/authority is part of this process of understanding what graphic design research is. An immediate response to this dilemma is that it is not a dilemma; for graphic designers and graphic design educators, of which there are very many, and graphic design researchers, of which there are seemingly very few, the term graphic design should not be problematic. What may be of concern is the way some argue for graphic design and other terminologies to be interchangeable. For example, in an article titled 'Research in Graphic Design', Sue Walker (2017) suggests that for "many ... the term "communication design" is synonymous with "graphic design"', expressing her preference for the term 'communication design'. As a REF2014 panel member, Walker's view here reflects the perspective of the REF2014 report which refers to 'graphic and communication design'. It is the case that some graphic design degree programmes have changed their name to communication design - for example, this has been a trend in Australia - but it remains that this should not be problematic for graphic design education, practice and research in that communication design, and the many other variations on the theme that have emerged since the early 1990s, must still define how they differ from graphic design.

It is not enough for advocates of communication design to say it 'essentially involves the production of visual solutions to communication problems' (Kennedy, 2011: 4). This is not sufficiently 
differentiated from what graphic design is understood to be. From the same source, the Icograda Design Education Manifesto 2011 speculates that the term 'graphic design' has evolved into a plural state of being with many names - graphic communication, visual communication, visual design, communication design, and the term identified as most appropriate by the Icograda General Assembly 2007 in La Habana is 'communication design'. Again, this should not concern graphic design educators as Icograda itself stood for the International Congress of Graphic Design Associations, placing graphic design at the root of all contemporary interpretations. What should be a concern is when graphic design is depreciated at the expense of new preferences. For example, a desire to champion communication design at the expense of graphic design relegates graphic design as defining the 'object' created by 'visual communication design' (Frascara 2004). This serves to demonstrate how unstable language is at discipline level, meaning the nomenclature associated REF submission might be confusing for panel members.

Teaching workload was also acknowledged by focus group participants as a key contributor to poor performance in REF. The amount of time apportioned to teaching ranges considerably across the sector, but few graphic design educators enjoy the privileges of a workload in research intensive universities where time available for research (on a research and teaching contract) could be as much as $40 \%$ of their yearly workload. The majority of graphic design is taught in the post-92 sector where workload is determined by University College Union recommendations that stipulate a minimum requirement for workload planning:

Work plans should allow sufficient time for scholarship and professional activities for academic (including teaching and scholarship, hourly paid and part time staff) and academic related staff. This may entail reducing elements of routine administration and ensuring there is sufficient time for academic and professional activities. One aspect of this in the case of the post 92 contract for England and Wales is the protection of the period (approximately 4 weeks and 3 days) for self directed research, scholarship and professional development. (https://www.ucu.org.uk)

Consequently, a majority of lecturers in graphic design (and other subjects in art and design) at universities in the UK are limited by this stipulation and in some cases graphic design academics confess that they are required to undertake self-directed research, scholarship and professional development in a block of time during the summer months. Research, of course, is not a seasonal activity so it should not be surprising that time is committed to little more than developmental activities that shun research (Harland, 2017). Add to this the burden of additional duties needing attention outside of a typical 30-week teaching year, such as degree shows or industry focused events such as D\&AD New Blood or New Designers, and the picture further unfolds. Such activities maintain good links with industry and alumni, but at the same time accentuate an industry facing education system that does not embrace academic research.

While the practice of what is now called graphic design dates back 5000 years or so (Friedman 1998: 85), the subject taught at university is relatively young and just decades rather than centuries old. Unsurprisingly, a culture of research practice is yet to emerge in this young discipline. Its credentials as a branch of design history are established through a small number of histories written since the early 1980s, but practice-based research degrees are in their relative infancy. Thus, it is difficult to foresee where graphic design academics can benefit from established researchers who participate in university REF teams.

Having expressed these initial concerns the focus group turned their attention to discussion about the early data analysis activities. With the intention to move the conversation on, the session convenors informed the focus group that keyword searches for generic terms often revealed outputs from other disciplines using graphic design terminology but without evidence of specific graphic design input. Interior design and product design were cited as examples. One immediate benefit from the focus group was that graphic design educators offered new key words to the initial listing in 
Table 2. Additions included book design, exhibition design, graphic novel, notational systems, page design, printmaking, signpost/signposting and visual information. Book design, exhibition design, signposting, visual information, did not identify any new outputs; graphic novel increased the number of outputs already found from 6 to 10; notational systems and page design did not register.

This distinct lack of contextualisation of 'graphic design research' means that graphic design outputs were in the most part invisible. Conversely, during the discussion, exhibition design was cited as an example of a subject that is more than a presentation service. This is understood as part of a researcher's practice-based submission and offers a useful comparison for future practice-based graphic design research outputs. Coupled with clear statements about the inclusion of graphic design methodology in research proposals, the recontextualisation of practice, definitions about graphic design's own pursuit of knowledge and its approaches to ontology, epistemology, and methodology, physical evidence as required, and explicit statements about research context, provide some indication about how to make graphic design more accountable as well as visible.

The focus group also concentrated on why graphic design outputs that could be found scored low on the 1-4* scale, and how this might be remedied. Suggestions included acknowledgment that graphic design academics publish in many domains; more multidisciplinary recognition in the research design and publication phases, including claiming research territory; providing nomenclature that helps other disciplines extend theirs through greater involvement in the writing-up phase of research. Walker (2017) has also observed the limited number of high quality journals dedicated to graphic design that offer good image reproduction.

When the discussion moved on to locating graphic design research, as in 'where is it?', the discussion was much less fruitful. A range of sources were suggested beyond the discipline for where it should or could be, such as the Journal of Art Research or Cultural Geography, and the most highly regarded design research journals such as Visible Language, but little else. Additionally, it was a concern that despite the size of the graphic design education community there has been limited published research on pedagogy. Finally, there was some acknowledgement that industry is employing research but it is not trickling down to education and teaching.

\section{Summary}

In REF2014, the graphic and communication design submission was referred to as weak, despite some notable exceptions such as that made by the Department of Typography and Graphic Communication at the University of Reading (rated at the top of the UoA34 table). This followed a similarly poor performance in the equivalent 2008 Research Assessment Exercise. There has been no response from the graphic design community about this state of play, and only very recently has there been any recognition that there might be such a thing as graphic design research, even if graphic design is often conflated with communication design. It is appropriate that graphic design educators respond to this scenario and with very limited research resource, this paper reports on a project undertaken by graphic design academics that examines, first, the REF 2014 submission data, and second, discussion stemming from focus group research undertaken at the most recent Graphic Design Educators' Network conference.

As this paper is only able to report on progress, we have identified a few next steps to take the data analysis aspect of the project forward. There is a need for further work to refine the dataset and remove outputs from other disciplines; keyword searches need clustering to provide data suitable for mapping; more analysis of the use of double weighting in Graphic Design outputs versus the UoA34 as a whole. Finally, the UoA34 sub-panel overview report states that 'a significant number of research outputs were of an interdisciplinary nature (although not necessarily identified as such by submitting HEIs) and were in the form of collaborative, team-driven projects' (REF2015: 84). Initial results suggests Graphic Design research often contributes to collaborative / interdisciplinary projects. Since HEls were not consistent in their use of the 'Is Interdisciplinary' check box on submission, outputs need to be reviewed by two methods (a) use of interdisciplinary check box and 
(b) usage of the terms interdisciplinary, multidisciplinary, transdisciplinary and cross-disciplinary in additional details.

A key early recommendation by the project team is that graphic design research, either independently or as part of another subject submission to research assessment exercises, must be labelled 'graphic design research'. If this happens, more understanding about what graphic design research looks like will emerge, more advice will be available to the graphic design research community to establish the sort of practice that graphic design research can be and some common ground might be identified. And, it should help differentiate graphic design from communication design. This is a challenge graphic design researchers must meet if the discipline is to be considered more concerned with the production of new knowledge rather than the presentation of new knowledge.

What emerges at this early stage of the project is that categories of design research that have much less history, such as co-design, design thinking, or service design have not been inclined to acknowledge the role of graphic design in their discourse. And yet it is there as noted by Walker (2017: 550). Furthermore, the idea of a graphic design research agenda undertaken by graphic design research groups seems to be unheard of despite the large number of academics and students working in the sector. Graphic design programme teams are not engaging enough with a national graphic design research agenda, not to mention their own individual research commitments.

Finally, concerns about graphic design research run much deeper than REF performance, and we have concentrated here on why things are the way they are rather than pointing towards where graphic design research can be found. Although responses to this concern must come from the graphic design education community, accountability and answers must also come from those who determine the working conditions of graphic design educators. These respective positions individual and institutional - can together rethink concerns about nomenclature and workload to not only provide better understandings for the next REF, but also lay more concrete foundations for subsequent research reviews.

\subsection{References}

Bernstein, B. (2000). Pedagogy, Symbolic Control and Identity, London: Rowman \& Littlefields.

Drucker, J. (2014). Graphesis: Visual Forms of Knowledge Production. London, England and Cambridge, Massachusetts: Harvard University Press.

Frascara, J. (2004). Communication Design: Principles, Methods and Practice (3rd edition). New York: Allworth Press.

Friedman, K. (1998). Building Cyberspace. Information, Place and Policy. Built Environment, 24(2/3), pp. 83103.

Kennedy, R. Our commitment to design education and research, in Bennett, A. G., and Vulpinari, O. (2011). Icograda Design Education Manifesto 2011, https://www.academia.edu/26706510/ICOGRADA_Design_Education_Manifesto_2011?auto=do wnload.

Harland, R. G. (2016). Graphic Design in Urban Environments. London: Bloomsbury Academic.

Harland, R. G. (2017). Reflections on Workload. Graphic Design Educators' Network Annual Conference, Sheffield Hallam University, 7-8 September. 
HEFCE2014 (2014). Research Excellence Framework 2014: Overview report by Main Panel D and Sub-panels 27 to 36.

http://www.ref.ac.uk/2014/media/ref/content/expanel/member/Main\%20Panel\%20D\%20overvi ew\%20report.pdf. Accessed 29 October 2017.

Muratovski, G. (2016). Research for Designers: a Guide to Methods and Practice. London: SAGE Publications Ltd.

REF2104 Unit of Assessment 34 - Art and Design: History, Practice and Theory. http://results.ref.ac.uk/DownloadSubmissions/ByUoa/34. Accessed 29 October 2017.

van der Waarde, K. (2009). On graphic design: listening to the reader. Avans Hogeschool Research Group Visual Rhetoric AKV | St. Joost.

Walker, S. (2017). Research in Graphic Design. The Design Journal, 20(5), 549-559.

doi.org/10.1080/14606925.2017.1347416

\section{Acknowledgments}

This project has been sponsored by The Council for Higher Education in Art and Design (CHEAD), the Art and Design Research Centre (ADRC) at Sheffield Hallam University and the Graphic Design Educators' Network (GDEN). Thanks to Neil Leonard for note taking during the focus group session at the Graphic Design Educators' Network Annual Conference, Sheffield Hallam University.

\section{About the Authors}

Robert Harland is a Senior Lecturer in the School of the Arts, English and Drama, Loughborough University, where his research is concerned with the role of graphic design in urban environments. He is chair of the Graphic Design Educators' Network.

James Corazzo is an educator, designer, and researcher. He is a Principal Lecturer in Graphic Design and Departmental Lead for Learning, Teaching and Assessment at Sheffield Hallam University. He is a founding member of the Graphic Design Educators' Network.

Ian Gwilt is Professor of Design at the University of South Australia. His research spans design research, visual communication design, information/data design, design in healthcare, co-design, mixed and augmented reality in creative practice and creative applications of $3 \mathrm{~d}$ printing.

Alison Honnor is an Impact Researcher at Sheffield Hallam University where she supports the Cultural, Communication and Computing Research Institute in maximising impact across Fine Art, Design, Film and Media Production, Journalism, Public Relations, Media Studies, Communication, Security and Computing.

Steve Rigley is a designer, lecturer and writer at Glasgow School of Arts, where he leads the Graphic Design pathway. He has contributed to a number of journals and conferences including the Association Typographique Internationale, AIGA and the World Design Congress. 